\section{CardioRenal Medicine}

Cardiorenal Med 2016;6:209-215

\title{
Circadian Blood Pressure Rhythm Is Changed by Improvement in Hypoalbuminemia and Massive Proteinuria in Patients with Minimal Change Nephrotic Syndrome
}

\author{
Daisaku Ando Gen Yasuda \\ Division of Nephrology and Hypertension, Yokohama City University Center Hospital, \\ Yokohama, Japan
}

\section{Key Words}

Ambulatory blood pressure - Nephrotic syndrome - Hypoalbuminemia - Glomerulonephritis . Proteinuria

\begin{abstract}
Background: Proteinuria and nighttime blood pressure (BP) elevation are notable risk markers of chronic kidney disease and correlate closely with each other. However, daily urinary protein excretion (UPE) always fluctuates. In patients with minimal change nephrotic syndrome (MCNS), serum albumin concentrations (SAC) decrease but fluctuate less than UPE. We evaluated whether $S A C$ is a reliable marker for proteinuria, and compared the relations among circadian BP changes, SAC, and UPE. Methods: In patients with MCNS (12 men and 11 women, $43 \pm 18$ years), blood and spot urine samples were collected on three consecutive days before treatment, and 24-hour BP was also measured on the three days. Then, an intervention study was conducted in the patients to examine circadian BP changes induced by treatment. Sleeping/waking BP ratio was analyzed as an indicator of circadian BP rhythm. Results: In the threeday measurements before treatment, mean coefficient of variation, an index of dispersion of data, for SAC was $7.4 \pm 7.4 \%$, which was markedly lower $(p<0.01)$ than $35.7 \pm 15.4 \%$ for UPE. SAC correlated inversely with sleeping/waking systolic and diastolic BP ratios on all three days, whereas UPE did not correlate significantly with sleeping/waking diastolic BP ratio on day 3 . Sleeping/waking systolic and diastolic BP ratios were $96 \pm 5$ and $95 \pm 6 \%$, and were higher $(p<0.05)$ than in healthy subjects ( $89 \pm 8$ and $88 \pm 10 \%)$. Treatment improved hyperproteinuria and hypoalbuminemia, and was accompanied by decreases $(p<0.05)$ in sleeping and waking systolic/diastolic BP ratio to $91 \pm 8$ and $89 \pm 9 \%$. Conclusion: These findings suggest that reduced SAC in patients with proteinuria is associated with disrupted circadian BP rhythm.
\end{abstract}




\section{CardioRenal Medicine}

\section{Introduction}

Proteinuria is a known predictor of renal damage as well as cardiovascular disease, and has been demonstrated to correlate closely with the loss of nocturnal blood pressure (BP) decline $[1,2]$. However, it is also well known that the daily urinary protein excretion (UPE) fluctuates even when calculated as a ratio to urinary creatinine concentration to reduce daily variability. Thus a question arises as to how precisely the fluctuating daily UPE is synchronized to subtle changes in circadian BP. Besides, in patients with chronic kidney disease (CKD) caused by glomerulonephritis, UPE ranges widely from $30-300 \mathrm{mg} /$ day to massive proteinuria, and sometimes exceeds $10 \mathrm{~g} /$ day. In such CKD patients, serum albumin concentrations (SAC) always change in proportion to urinary protein levels, showing an inverse relationship. However, SAC do not fluctuate as much as UPE. Thus, there is a possibility that SAC reflect more accurately the relationship between circadian BP change and proteinuria.

Nephrotic syndrome is one of the CKD that show a wide range of proteinuria. If proteinuria is associated with circadian BP changes, the coexisting hypoalbuminemia may also be associated with 24-hour BP rhythm. However, few studies have focused on the relation of SAC as well as proteinuria with the circadian BP rhythm in patients with massive proteinuria, such as minimal change nephrotic syndrome (MCNS). Besides, no studies have assessed how treatment of proteinuria and hypoalbuminemia influences 24-hour BP rhythm. Whether dynamic changes in UPE and SAC through treatment affect the circadian BP rhythm can only be evaluated in patients with massive proteinuria, such as MCNS. We thus focused on these patients in the present study. The aims of the study were to examine, first, how proteinuria fluctuates in daily examinations; second, whether SAC is a reliable surrogate marker for proteinuria for comparing the relation between circadian BP changes and UPE, and third, how improvements of hypoalbuminemia and hyperproteinuria influence circadian BP patterns.

\section{Methods}

\section{Patient Selection}

Among subjects aged between 18 and 70 years who were referred to our hospital because of clinical symptoms such as edema and abnormal urinalysis found at primary care physicians' offices, patients diagnosed with MCNS were eligible for the study. MCNS was diagnosed by biopsy-based pathologic findings in all patients. The inclusion criteria were: serum total protein concentration $<6.0 \mathrm{~g} / \mathrm{dl}$, SAC $<3.0 \mathrm{~g} / \mathrm{dl}$, UPE $>3.5$ $\mathrm{g} / \mathrm{g}$ creatinine, estimated glomerular filtration rate $(\mathrm{eGFR}) \geq 30 \mathrm{ml} / \mathrm{min} / 1.73 \mathrm{~m}^{2}$, and office systolic BP $<140$ $\mathrm{mm} \mathrm{Hg}$ or diastolic BP $<90 \mathrm{~mm} \mathrm{Hg}$. Patients were excluded if they had the following complications: malnutrition; protein-losing enteropathy; tubulointerstitial nephritis; endocrinological, hematological, hepatic or immune disease; abnormal thyroid function; other major diseases. Patients who were taking antihypertensive medications and/or immunosuppressive agents at enrollment were also excluded. Informed consent was obtained from each subject. This study was approved by the Ethics Committee of the Yokohama City University.

\section{Study Design}

The study was an intervention trial with intention-to-treat analysis in patients with MCNS to examine the changes in circadian BP rhythm before and after treatment. Before treatment, blood and spot urine samples were collected on three consecutive days for SAC and urinary protein-to-creatinine ratio determinations. During these three consecutive days, ambulatory 24-hour BP monitoring (ABPM) was also performed (first ABPM).

Patients initially received cyclosporine (2-3 mg/kg/day) and prednisolone (30-40 mg/day) combination therapy, or prednisolone monotherapy. The prednisolone and cyclosporine doses were tapered by 5-10 and $25 \mathrm{mg}$, respectively, every 4-8 weeks according to the UPE. Medications were discontinued when remission was confirmed clinically. All patients underwent the second ABPM as well as blood and urine examinations between 6 and 24 months of treatment, regardless of whether or not they had remission. 


\section{CardioRenal Medicine}

\begin{tabular}{l|l}
\hline Cardiorenal Med 2016;6:209-215 \\
\hline DOI: 10.1159/000444095 & $\begin{array}{l}\text { ○ 2016 S. Karger AG, Basel } \\
\text { www.karger.com/crm }\end{array}$ \\
\hline $\begin{array}{l}\text { Ando and Yasuda: Circadian Blood Pressure Rhythm Is Changed by Improvement in } \\
\text { Hypoalbuminemia and Massive Proteinuria in Patients with Minimal Change Nephrotic } \\
\text { Syndrome }\end{array}$
\end{tabular}

Syndrome

Remission was defined as a decrease in UPE to $<300 \mathrm{mg} / \mathrm{g}$ creatinine on three consecutive visits. To avoid false results caused by fluctuation in proteinuria, remission had to persist at least 1 month. Subjects who did not fulfill the criteria of remission were classified into the nonremission group. Fifty-three age- and sexmatched healthy subjects (office systolic BP $<140 \mathrm{~mm} \mathrm{Hg}$ and diastolic BP $<90 \mathrm{~mm} \mathrm{Hg}$, eGFR $>60 \mathrm{ml} / \mathrm{min}$ / $1.73 \mathrm{~m}^{2}$, UPE $<30 \mathrm{mg} / \mathrm{g}$ creatinine) were recruited as a nontreated control group. The control subjects underwent blood and urine examinations and ABPM.

Biochemical Examinations

Biochemical parameters in blood and urine specimens were analyzed using an autoanalyzer (Hitachi 7250, Hitachi, Tokyo, Japan). UPE was expressed as urinary protein-to-creatinine excretion ratio. Logarithmic transformation (log) of urinary protein-to-creatinine ratio and coefficient of variation, an index of dispersion of data series around the mean, were calculated for each individual.

\section{$A B P M$ and Data Processing}

ABPM was performed using noninvasive BP recorders (TM2425, A\&D, Tokyo, Japan). The reliability of the devices has been evaluated [3]. BP was measured at 15-min intervals from 07:00 to 21:00 and at 30-min intervals from 21:00 to 07:00. Waking and sleeping time BP were obtained as the average values during the waking and sleeping periods, respectively. Then, sleeping/waking BP ratios were analyzed as an index of circadian BP rhythm. ABPM was repeated in patients who had $>20 \%$ missing values out of the expected number of readings, $>30 \%$ error rate for total readings, or missing values for more than two consecutive hours.

\section{Statistical Analysis}

Normally distributed parameters are presented as mean \pm SD. Skewed distribution was normalized by logarithmic transformation before analyses. Coefficient of variation was calculated by SD divided by the mean. The correlation between two parameters was examined based on Pearson's correlation analysis. The differences in baseline parameters between two groups were assessed by the nonparametric Mann-Whitney's U test. Data obtained before and after therapy were analyzed using the Wilcoxon signed-rank test. A two-side $\mathrm{p}$ value less than 0.05 was considered statistically significant. Statistical analyses were performed using SPSS version 23 (SPSS, Chicago, Ill., USA).

\section{Results}

Relationship between SAC and Fluctuating UPE in MCNS Patients

Twenty-three patients with MCNS (12 men and 11 women; age $43 \pm 18$ years, range 18-69 years), who fulfilled the criteria were enrolled in the study. In these patients, SAC (mean \pm SD) on three consecutive days before treatment were $1.84 \pm 0.74$ (first day), $1.87 \pm$ 0.70 (second day) and $1.81 \pm 0.71 \mathrm{~g} / \mathrm{dl}$ (third day). The corresponding UPE were 8.7 $\pm 5.5,7.6$ \pm 5.4 and $8.2 \pm 5.6 \mathrm{~g} / \mathrm{g}$ creatinine, and $\log$ UPE were $3.85 \pm 0.28,3.77 \pm 0.32$ and $3.80 \pm 0.34$ $\mathrm{mg} / \mathrm{g}$ creatinine. A significant inverse correlation was observed between SAC and UPE on each of the three consecutive days (first day: $r=-0.477, p=0.021$; second day: $r=-0.454$, $\mathrm{p}=0.030$; third day: $\mathrm{r}=-0.453, \mathrm{p}=0.030$ ). A significant inverse correlation was also found between SAC and $\log$ UPE (first day: $r=-0.526, p=0.010$; second day: $r=-0.564, p=0.005$; third day: $\mathrm{r}=-0.532, \mathrm{p}=0.009$ ). For the three days, day-to-day coefficient of variation for SAC was $7.4 \pm 7.4 \%$, which was markedly lower $(\mathrm{p}<0.001$ ) than $35.7 \pm 15.4 \%$ for UPE, but was similar to that for log UPE $(4.3 \pm 1.9 \%, \mathrm{p}=0.121)$.

\section{Relationship between Sleeping/Waking BP Ratio and SAC or UPE}

In all patients, SAC correlated inversely with sleeping/waking systolic and diastolic BP ratios on all three consecutive days (table 1), whereas UPE did not correlate with sleeping/ waking diastolic BP ratio on the third day. Log UPE correlated with sleeping/waking systolic and diastolic BP ratios on three consecutive days (table 1). 
Ando and Yasuda: Circadian Blood Pressure Rhythm Is Changed by Improvement in Hypoalbuminemia and Massive Proteinuria in Patients with Minimal Change Nephrotic Syndrome

Table 1. Relationship between sleeping/waking BP ratio and SAC or urinary protein-to-creatinine ratio measured on three consecutive days in 23 patients with MCNS

\begin{tabular}{|c|c|c|c|c|}
\hline & \multicolumn{2}{|c|}{ Sleeping/waking systolic BP ratio } & \multicolumn{2}{|c|}{ Sleeping/waking diastolic BP ratic } \\
\hline & $\mathrm{r}$ & $\mathrm{p}$ & $\mathrm{r}$ & $\mathrm{p}$ \\
\hline \multicolumn{5}{|l|}{ SAC } \\
\hline 1st day & -0.572 & 0.004 & -0.503 & 0.014 \\
\hline 2nd day & -0.534 & 0.009 & -0.457 & 0.028 \\
\hline 3rd day & -0.572 & 0.004 & -0.476 & 0.022 \\
\hline \multicolumn{5}{|c|}{ Urinary protein-to-creatinine ratio } \\
\hline 1st day & 0.570 & 0.005 & 0.544 & 0.007 \\
\hline 2nd day & 0.472 & 0.023 & 0.487 & 0.018 \\
\hline 3rd day & 0.435 & 0.038 & 0.344 & 0.108 \\
\hline \multicolumn{5}{|c|}{ Log urinary protein-to-creatinine ratio } \\
\hline 1 st day & 0.614 & 0.002 & 0.547 & 0.007 \\
\hline 2nd day & 0.491 & 0.017 & 0.491 & 0.017 \\
\hline 3rd day & 0.486 & 0.019 & 0.432 & 0.040 \\
\hline
\end{tabular}

Table 2. Comparisons of clinical parameters before and after treatment in patients with MCNS, and between MCNS before treatment and healthy control subjects

\begin{tabular}{|c|c|c|c|c|c|}
\hline \multirow[t]{2}{*}{ Parameter } & \multicolumn{3}{|l|}{ MCNS } & \multicolumn{2}{|c|}{ Control subjects } \\
\hline & $\begin{array}{l}\text { before } \\
\text { treatment }\end{array}$ & $\begin{array}{l}\text { after } \\
\text { treatment }\end{array}$ & $\begin{array}{l}\mathrm{p} \text { before } \\
\text { vs. after } \\
\text { treatment }\end{array}$ & value & $\begin{array}{l}\mathrm{p} \text { vs. MCNS } \\
\text { before } \\
\text { treatment }\end{array}$ \\
\hline Number of subjects & 23 & 23 & & 53 & \\
\hline Age, years & $43 \pm 18$ & $44 \pm 19$ & & $46 \pm 15$ & 0.317 \\
\hline Men/women & $12 / 11$ & $12 / 11$ & & $25 / 28$ & 0.661 \\
\hline Office systolic $\mathrm{BP}, \mathrm{mm} \mathrm{Hg}$ & $132 \pm 13$ & $134 \pm 16$ & 0.831 & $128 \pm 16$ & 0.296 \\
\hline Office diastolic BP, $\mathrm{mm} \mathrm{Hg}$ & $78 \pm 9$ & $78 \pm 9$ & 0.317 & $70 \pm 9$ & $<0.001$ \\
\hline Waking systolic BP, mm Hg & $133 \pm 13$ & $136 \pm 16$ & 0.670 & $134 \pm 15$ & 0.919 \\
\hline Waking diastolic BP, $\mathrm{mm} \mathrm{Hg}$ & $81 \pm 10$ & $80 \pm 10$ & 0.855 & $77 \pm 8$ & 0.116 \\
\hline Sleeping systolic BP, mm Hg & $128 \pm 13$ & $124 \pm 18$ & 0.316 & $119 \pm 17$ & 0.024 \\
\hline Sleeping diastolic $\mathrm{BP}, \mathrm{mm} \mathrm{Hg}$ & $77 \pm 11$ & $72 \pm 11$ & 0.073 & $69 \pm 10$ & 0.003 \\
\hline Difference between sleeping and waking systolic BP, mm Hg & $7.7 \pm 13.9$ & $14.2 \pm 15.7$ & 0.041 & $12.1 \pm 11.2$ & 0.008 \\
\hline Difference between sleeping and waking diastolic BP, $\mathrm{mm} \mathrm{Hg}$ & $7.0 \pm 13.3$ & $11.3 \pm 10.9$ & 0.049 & $7.7 \pm 7.5$ & 0.050 \\
\hline Sleeping/waking systolic BP ratio, \% & $96 \pm 5$ & $91 \pm 8$ & 0.042 & $89 \pm 8$ & $<0.001$ \\
\hline Sleeping/waking diastolic BP ratio, \% & $95 \pm 6$ & $89 \pm 9$ & 0.039 & $88 \pm 10$ & 0.006 \\
\hline Serum albumin, g/dl & $1.8 \pm 0.6$ & $3.4 \pm 0.9$ & $<0.001$ & $4.3 \pm 0.8$ & $<0.001$ \\
\hline $\mathrm{eGFR}, \mathrm{ml} / \mathrm{min} / 1.73 \mathrm{~m}^{2}$ & $77 \pm 17$ & $75 \pm 20$ & 0.910 & $71 \pm 15$ & 0.372 \\
\hline Log urinary protein-to-creatinine ratio, $\mathrm{mg} / \mathrm{g}$ creatinine & $3.7 \pm 0.4$ & $2.3 \pm 0.8$ & $<0.001$ & & \\
\hline
\end{tabular}

\section{Clinical Parameters and Circadian BP Changes in Patients with MCNS before and after}

Treatment

Clinical parameters in MCNS patients before treatment and those obtained from 53 healthy control subjects were compared (table 2). Office diastolic BP was higher in the MCNS group before treatment than that in the control group, but office systolic BP was not significantly different between the two groups. Sleeping systolic and diastolic BP in MCNS patients before treatment were higher than those in controls, but waking systolic and diastolic BP were not different. Consequently, differences between sleeping and waking systolic BP were 


\section{CardioRenal Medicine}

\begin{tabular}{l|l}
\hline Cardiorenal Med 2016:6:209-215 \\
\hline DOI: 10.1159/000444095 & $\begin{array}{l}\text { @ 2016 S. Karger AG, Basel } \\
\text { www.karger.com/crm }\end{array}$ \\
\hline $\begin{array}{l}\text { Ando and Yasuda: Circadian Blood Pressure Rhythm Is Changed by Improvement in } \\
\text { Hypoalbuminemia and Massive Proteinuria in Patients with Minimal Change Nephrotic } \\
\text { Syndrome }\end{array}$
\end{tabular}

Table 3. Comparisons of clinical parameters before and after treatment in patients with MCNS based on the remission criterion of UPE $<300 \mathrm{mg} / \mathrm{g}$ creatinine

\begin{tabular}{|c|c|c|c|c|c|c|}
\hline \multirow[t]{2}{*}{ Parameter } & \multicolumn{3}{|l|}{ Remission } & \multicolumn{3}{|c|}{ Nonremission } \\
\hline & $\begin{array}{l}\text { before } \\
\text { treatment }\end{array}$ & $\begin{array}{l}\text { after } \\
\text { treatment }\end{array}$ & $\mathrm{p}$ & $\begin{array}{l}\text { before } \\
\text { treatment }\end{array}$ & $\begin{array}{l}\text { after } \\
\text { treatment }\end{array}$ & $\mathrm{p}$ \\
\hline Number of subjects & 13 & 13 & & 10 & 10 & \\
\hline Age, years & $43 \pm 18$ & $44 \pm 18$ & & $42 \pm 19$ & $43 \pm 19$ & \\
\hline Men/women & $6 / 7$ & $6 / 7$ & & $6 / 4$ & $6 / 4$ & \\
\hline Waking systolic BP, mm Hg & $132 \pm 12$ & $138 \pm 17$ & 0.173 & $136 \pm 13$ & $132 \pm 15$ & 0.575 \\
\hline Waking diastolic BP, $\mathrm{mm} \mathrm{Hg}$ & $78 \pm 8$ & $80 \pm 7$ & 0.152 & $85 \pm 12$ & $82 \pm 13$ & 0.241 \\
\hline Sleeping systolic BP, mm Hg & $125 \pm 10$ & $122 \pm 8$ & 0.975 & $132 \pm 16$ & $125 \pm 17$ & 0.203 \\
\hline Sleeping diastolic BP, $\mathrm{mm} \mathrm{Hg}$ & $73 \pm 9$ & $69 \pm 8$ & 0.753 & $82 \pm 12$ & $76 \pm 13$ & 0.169 \\
\hline Sleeping/waking systolic BP ratio, \% & $95 \pm 6$ & $89 \pm 9$ & 0.044 & $97 \pm 4$ & $95 \pm 5$ & 0.721 \\
\hline Sleeping/waking diastolic BP ratio, $\%$ & $94 \pm 6$ & $87 \pm 10$ & 0.133 & $96 \pm 6$ & $93 \pm 7$ & 0.386 \\
\hline $\mathrm{SAC}, \mathrm{g} / \mathrm{dl}$ & $1.7 \pm 0.5$ & $3.8 \pm 0.8$ & 0.002 & $1.8 \pm 0.7$ & $3.0 \pm 0.9$ & 0.013 \\
\hline $\mathrm{eGFR}, \mathrm{ml} / \mathrm{min} / 1.73 \mathrm{~m}^{2}$ & $78 \pm 18$ & $75 \pm 15$ & 0.530 & $72 \pm 17$ & $76 \pm 24$ & 0.721 \\
\hline Log urinary protein-to-creatinine ratio, $\mathrm{mg} / \mathrm{g}$ creatinine & $3.7 \pm 0.5$ & $1.7 \pm 0.3$ & $<0.001$ & $3.8 \pm 0.3$ & $3.5 \pm 0.5$ & 0.051 \\
\hline
\end{tabular}

lower and sleeping/waking systolic and diastolic BP ratios were higher in MCNS patients before treatment compared to controls. Serum albumin was significantly lower in MCNS patients before treatment compared to controls, but eGFR was not significantly different.

Treatment of MCNS patients significantly improved SAC and log UPE, with no change in eGFR compared to before treatment (table 2). After treatment, differences between sleeping and waking systolic BP increased and sleeping/waking systolic and diastolic BP ratios decreased significantly compared to before treatment.

The changes in clinical parameters in the remission and nonremission groups are shown in table 3. Thirteen patients entered complete remission. In these patients, sleeping/waking systolic BP ratio decreased significantly, while SAC increased and UPE decreased after treatment. Ten patients did not achieve remission and showed no significant changes in sleeping/waking systolic and diastolic BP ratios after treatment. Some patients were on maintenance doses of prednisolone, and the doses in the remission and nonremission groups were, respectively, $5.3 \pm 4.9$ and $5.1 \pm 5.0 \mathrm{mg} /$ day $(\mathrm{p}=0.834)$, showing no difference. Apart from prednisolone, no other immunosuppressive medications including cyclosporine and no antihypertensive agents were taken at the second ABPM. There were no changes in waking and sleeping systolic and diastolic BP and eGFR after treatment compared to before treatment, regardless of treatment outcome.

\section{Discussion}

In patients with MCNS, we observed a more reliable correlation between SAC and sleeping/waking BP ratio than between urinary protein-to-creatinine ratio and sleeping/ waking BP ratio. In these patients, improvements in hyperproteinuria and hypoalbuminemia by treatment were associated with changes in sleeping/waking BP ratio, although waking and sleeping systolic and diastolic BP were not changed by treatment. These findings suggest that sleeping/waking BP ratio as an index of circadian BP rhythm is related closely to the extent of decrease in SAC and increase in UPE. It has been difficult so far to evaluate the relation between SAC and circadian BP pattern without taking proteinuria into account. Only a few 
Ando and Yasuda: Circadian Blood Pressure Rhythm Is Changed by Improvement in Hypoalbuminemia and Massive Proteinuria in Patients with Minimal Change Nephrotic Syndrome

studies reported the association of SAC with less dipping BP [4]. To the best of our knowledge, this is the first report that circadian BP rhythm is associated with dynamic changes in UPE and SAC.

$\mathrm{BP}$ regulation is determined principally by the circulating blood volume, peripheral resistance, cardiac output, and neurohumoral factors. Serum albumin influences circulating blood volume and neurohumoral factors as well as renal plasma flow through changing plasma oncotic pressure. According to the classical underfill theory [5], reduction of plasma oncotic pressure transfers intravascular fluid into the interstitium and decreases plasma volume, stimulating neurohumoral factors. Another possible intrarenal mechanism (overfill theory) is sodium and water retention with normal or expanded blood volume. Proteinuria may not directly affect these factors but exerts indirect effects through hypoalbuminemia. Thus, to evaluate the circadian BP changes, SAC may be a more precise and reliable marker of UPE status than UPE itself. At least, SAC should be taken into consideration as an additional indicator for proteinuria. It is well known that patients with greater UPE have a poor renal prognosis [6]. Hence, SAC may also be considered to be a prognostic factor for renal function. Further prospective studies should be performed to confirm whether circadian BP rhythm is influenced by changes in SAC in patients with proteinuria and patients with hypoalbuminemia caused by diseases other than CKD.

In the present study, we also observed that patients with massive proteinuria due to MCNS showed an increase in sleeping/waking BP ratio, an indicator of disturbed circadian $\mathrm{BP}$ rhythm. Thus, we evaluated whether changes in SAC and nephrogenic range UPE are associated with disturbed circadian BP variation by treatment. After hypoalbuminemia and hyperproteinuria were improved by treatment, sleeping/waking systolic and diastolic BP ratios also shifted close to the values in control subjects. In the MCNS patients studied, eGFR was not different from control subjects before treatment and did not change after treatment. These findings suggest that both hypoalbuminemia and hyperproteinuria are related to the circadian BP change. The nephrotic syndrome is a complex dysmetabolic disorder manifesting increased interstitial fluids together with changes in circulating blood volume and humoral factors $[7,8]$. Thus, the BP-regulating mechanisms under these specific hemodynamic conditions should be different from those in minor proteinuria, resulting in loss of nighttime BP fall. In these patients including those with MCNS, serum albumin may play an important role in regulating the circadian BP rhythm.

Recently, low SAC have been considered to play a key role in systemic vascular damage. Yokoyama et al. [9] reported that hypoalbuminemia is an independent predictor of diabetic nephropathy and impaired renal function. Zimmermann et al. [10] reported a negative correlation between SAC and C-reactive protein level, an indicator of inflammatory process of atherogenesis. In nephrotic syndrome, hypoalbuminemia contributes to an increase in cardiovascular disease by elevating lysophosphatidylcholine [11]. Considering these previous reports, we postulate that hypoalbuminemia is closely associated with vascular atherosclerosis and cardiovascular events, for which disturbed circadian BP rhythm is the crucial risk marker. Even though the range of SAC is narrow, Fung et al. [12] and Mehrotra et al. [13] reported that a decrease by as little as $0.2 \mathrm{~g} / \mathrm{dl}$ increases cardiovascular risk and mortality. Thus, our findings indicate that SAC alone should have potential influence on the circadian BP rhythm and consequently is a relevant predictor of cardiovascular disease.

\section{Limitations}

The second ABPM was performed after treatment while some patients were taking maintenance doses of prednisolone. Glucocorticoids may affect 24-hour BP rhythm, but the maintenance doses of prednisolone were not different between the remission and nonremission groups. This infers that the glucocorticoid effects on 24-hour BP regulation were minimal. 


\section{CardioRenal Medicine}

\begin{tabular}{l|l}
\hline \multicolumn{2}{l}{ Cardiorenal Med 2016;6:209-215 } \\
\hline DOI: 10.1159/000444095 & $\begin{array}{l}\text { C 2016 S. Karger AG, Basel } \\
\text { www.karger.com/crm }\end{array}$ \\
\hline
\end{tabular}

Ando and Yasuda: Circadian Blood Pressure Rhythm Is Changed by Improvement in Hypoalbuminemia and Massive Proteinuria in Patients with Minimal Change Nephrotic Syndrome

In conclusion, our study in MCNS patients suggests that SAC may be a reliable marker of massive proteinuria, and that both hypoalbuminemia and massive proteinuria disrupt the circadian BP rhythm. However, to confirm our hypothesis, a larger number of subjects with massive proteinuria or hypoalbuminemia of various nonrenal causes should be evaluated.

\section{Disclosure Statement}

The authors report no conflicts of interest and have responsibilities for the content and writing of the paper.

\section{References}

1 Bianchi S, Bigazzi R, Baldari G, Sgherri G, Campese VM: Diurnal variations of blood pressure and microalbuminuria in essential hypertension. Am J Hypertens 1994;7:23-29.

2 Andoh D, Kobayashi M, Yasuda G, Hirawa N, Saka S, Yatsu K, Yamamoto Y, Umemura S: Loss of nocturnal decline of blood pressure in non-diabetic patients with nephrotic syndrome in the early and middle stages of chronic kidney disease. Hypertens Res 2009;32:364-368.

3 Yasuda G, Ando D, Hirawa N, Umemura S, Tochikubo 0: Effects of losartan and amlodipine on urinary albumin excretion and ambulatory blood pressure in hypertensive type 2 diabetic patients with overt nephropathy. Diabetes Care 2005;28:1862-1868.

4 Agarwal R, Andersen MJ: Correlates of systolic hypertension in patients with chronic kidney disease. Hypertension 2005;46:514-520.

5 Jager A, Kostense PJ, Ruhé HG, Heine RJ, Nijpels G, Dekker JM, Bouter LM, Stehouwer CD: Microalbuminuria and peripheral arterial disease are independent predictors of cardiovascular and all-cause mortality, especially among hypertensive subjects. Arterioscler Thromb Vasc Biol 1999;19:617-624.

6 Palmer BF, Alpern RJ: Pathogenesis of edema formation in the nephrotic syndrome. Kidney Int 1997;59:S21S27.

7 Koomans HA, Braam B, Geers AB, Roos JC, Mees EJD: The importance of plasma protein for blood volume and blood pressure homeostasis. Kidney Int 1986;30:730-735.

8 Vande Walle JGJ, Donckerwolcke RA: Pathogenesis of edema formation in the nephrotic syndrome. Pediatr Nephrol 2001;16:283-293.

9 Yokoyama H, Tomonaga O, Hirayama M, Ishii A, Takeda M, Babazono T, Ujihara U, Takahashi C, Omori Y: Predictors of the progression of diabetic nephropathy and the beneficial effect of angiotensin-converting enzyme inhibitors in NIDDM patients. Diabetologia 1997;40:405-411.

10 Zimmermann J, Herrlinger S, Pruy A, Metzger T, Wanner C: Inflammation enhances cardiovascular risk and mortality in hemodialysis patients. Kidney Int 1999;55:648-658.

11 Vuong TD, Stroes ES, Willekes-Koolschijn N, Rabelink TJ, Koomans HA, Joles JA: Hypoalbuminemia increases lysophosphatidylcholine in low-density lipoprotein of normocholesterolemic subjects. Kidney Int 1999;55: 1005-1010.

12 Fung F, Sherrard DJ, Gillen DL, Wong C, Kestenbaum B, Seliger S, Ball A, Stehman-Breen C: Increased risk for cardiovascular mortality among malnourished end-stage renal disease patients. Am J Kidney Dis 2002;40: 307-314.

13 Mehrotra R, Duong U, Jiwakanon S, Kovesdy CP, Moran J, Kopple JD, Kalantar-Zadeh K: Serum albumin as a predictor of mortality in peritoneal dialysis: comparisons with hemodialysis. Am J Kidney Dis 2011;58:418428. 